desire to add my testimony to Mr. Common's opinion (NATURE, vol. xxxiv. P. 470), that the conditions of the sky must have been wholly different; and where the visibility of the corona is in question, the atmospheric diffusion is all-important.

We have a most trustworthy criterion of the amount of diffused sky light in the visibility of the moon's limb outside the sun on the coronal background. This appears not to have been observed at all last August, and it may be useful to recall what it looked like under certain almost ideal conditions, which are not likely to recur.

On July 29,1878 , I observed it in the remarkably clear air of Colorado, and at an altitude of over 14,000 feet, on Pike's Peak, and have a vivid recollection of its appearance then. After totality, and while writing my notes, I heard a call from some bystander of "Look at the moon!" and glancing up from the paper (with an eye which could not have been in a sensitive condition), saw the moon's limb outside the sun, most conspicuously defined by a band of pearly light, which faded outward, but whose visible width can be estimated from the fact that though I went on intermittently with my notes, and took no other precaution to shield the eye than keeping it in the shadow cast by my telescope stand, the limb continued in my view under these unfavourable circumstances for four minutes and tzvelve seconds after totality was over. A similar duration was recorded by Gen. Myer, the Chief Signal Officer of the United States, who observed near me ; and others at a lower altitude certified to having observed it over three minutes. Something is due to the increased sensitiveness of the eye after the darkness, but there is no doubt that, with even the slight rest of the retina which totality afforded, the phenomenon was such a salient one as to force itself on the attention of those not regarding it.

This is for a very exceptionally pure sky, of course ; but if, as is stated, observers specially seeking it could not even see the limb a little outside the sun (where the corona is brightest) last August, it seems clear that no conclusions as to its non-visibility under any ordinary means are to be drawn from negative evidence of such a kind.

Allegheny Observatory, Allegheny, Pennyslvania

The Astronomical Theory of the Great Ice Age

IN your issue of November 4 (p. 7), my friend Mr. W. H. S. Monck asks one or two questions relative to the paper on "The Astronomical Theory of the Great Ice Age" which you did me the honour to reprint.

I take as a convenient unit the mean daily sun heat on one hemisphere. The amount of this unit is indicated by the fact that it continuously maintains the earth's temperature some $300^{\circ}$ more or less above what it would be were the sun's heat withdrawn.

The calculations I gave showed that in the glacial winter the mean daily receipt of heat sunk to 68 of a unit, while in the brief glacial summer the mean daily receipt was $\mathbf{I} 38$ unit.

Considering the magnitude of the unit, it is obvious that fluctuations like this must correspond to vast climatic changes of the kind postulated in the Ice age. Here it seems to me lies the great originaring cause of the Ice age, and to dwell on the minor phenomena merely obscures the real point.

If it be said that no great climatic change takes place because the total sun heat in the year remains the same, then I remark, as I did at the Royal Institution, that on this principle it would be the same thing to give a horse $\mathrm{I} 5$ lbs. of oats a day for six months and $5 \mathrm{lbs}$. a day for the other six months as to give him Io lbs. of oats a day all the year round. ROBERT S. BALL

The Observatory, co. Dublin, November I I

P.S.-I take this opportunity of correcting a misprint in my paper as given in NATURE (vol. xxxiv. p. 608). The maximum number of days' difference between summer and winter is $465 \times$ eccentricity.

\section{Abnormality in Cats' Paws}

AMONG the many interesting features suggested by the genealogical table in last week's NATURE (p. 40), showing the persistence of abnormality in the number of toes on a cat's paw, there is one the significance of which seems not to have occurred to, or to have been passed over by, Mr. Edward Poulton. The peculiarity I refer to is the larger percentage of abnormality among the female offspring than among the male. Taking "Tabby
$\mathrm{V}$." as a starting-point, and leaving out one zonormal kitten of which the sex was unnoted, as well as the families of which no particulars are given, the coral number of descendants in the table is 36 , of which 12 are males and 24 females. Of the $\mathbf{1 2}$ males, 5 are normal and 7 abnormal, or $4 \mathrm{I}_{3}^{\frac{2}{3}}$ and $58 \frac{1}{3}$ per cent. respectively; and among the 24 females 7 are normal and 17 abnormal, or $29^{\frac{1}{6}}$ and $70^{\frac{5}{6}}$ per cent. respectively. Or, to put it in another way, among the $I 2$ normal kittens 5 are males, 7 are females, or $41 \frac{2}{3}$ and $58 \frac{1}{3}$ per cent. respectively, instead of $33 \frac{1}{3}$ and $66_{3}^{2}$ per cent. as it should be ; and among the abnormals 7 are males and 17 females, or $29 \frac{1}{6}$ and $70 \frac{\pi}{6}$ per cent. instead of $33 \frac{1}{3}$ and $66^{\frac{2}{3}}$.

This would seem to indicate either (I) that there is a greater tendency among the male offspring than among the female to revert to the normal condition, or $(\boldsymbol{z})$ that there is a tendency among the offspring to inherit rather the peculiarities of the parent of their own sex-the male parent in all cases in the table being assumed to be normal. If rather, probably the former, though the latter could easily be tested by a similar set of observations with cats, the male parent of which was abnormal, the mothers being in each case normal.

Hatton Garden, London, E.C., November I5

$$
\text { J. Herbert Hodd }
$$

\section{Abnormalities in the Vertebral Column of the Common Frog}

IN preparing skeletons of the fror, my students came acro:s the following abnormalities in the vertebral column, a record of which may be not without interest:-

(I) In a large Rana temporaria, the centrum of the eighth vertebra, instead of being biconcave (amphiccelous), is concavoconvex (procoelous), like that of the preceding vertebra. This abnormality I have observed before.

(2) In a medium-sized Rana temporaria, the eighth and ninth vertebræ are both abnormal. The ninth vertebra has welldeveloped only one transverse process (the right) for articulation with the ilium. The other (the left) is quite small and illshapen; there is is no anterior zygapophysis on this side. The centrum is anteriorly convex on the right side and concave on the left side. Posteriorly, there is on the right side a convex articular surface for the urostyle; but on the left side the articular surface is ill-developed and irregular. In the eighth vertebra, the left transverse process is abnormally large and strong, has a marked backward direction, and has taken on itself the sacral function on this side, articulating with the ilium. The right transverse process is nearly, but not quite normal. There is a right, but no left, posterior zygapophysis. The anterior end of the centrum is normally concave; but the posterior end is convex on the left side and concave on the right side. The urostyle and the ilia are slightly modified in accordance with the abnormalities of the vertebræ.

University College, Bristol

\section{Influence of Wind on Barometric Readings}

Allow me a few words of supplement to Prof. Abbe's useful letter in NATURE of November II, p. 29.

Sir H. Tames's paper is perhaps better known on this side of the Atlantic than Prof. Abbe thinks ; but there undoubtedly is too great a tendency to rush into print without previously reading up what has been done. The great bibliographical work which the Signal Office has in hand will do more to check this evil than anything which could be suggested, and hence its enormous importance.

As regards the application of suction to anemometers, no reference is made to that of Bourdon, ${ }^{1}$ of which my friend Dr. Fines was recently kind enough to show me a very fine specimen at work at his observatory at Perpignan.

The Cowl Committee of the Sanitary Institute, far from being (as has been imagined) asleep or dead, has been very hard at work, and will in a few months report the result.

I sincerely hope that Lord Rayleigh will accede to Prof. Abbe's suggestion, but in the interim I append the report of Lord Rayleigh's Southampton paper which appeared in the Meteorological Masasine for October 1882, p. I30:-

" 'On the Effect of Wind on the Draught of Chimneys,' by Prof. Lord Rayleigh, F. R.S.

I See also Laughton, "Historical Sketch of Anemometry," Quart. Fourn. Roy. Met. Soc. vol. viii. (1882), p. 177 . 